Check for updates

London

Cite this as: BMJ 2021;373:n1005 http://dx.doi.org/10.1136/bmj.n1005 Published: 16 April 2021

\section{Covid-19: Risk of cerebral blood clots from disease is 10 times that from vaccination, study finds}

\author{
Ingrid Torjesen
}

Covid-19 is associated with a far greater risk of cerebral venous thrombosis than the vaccinations that protect against it, early research from the University of Oxford has shown.

The results, available as a non-peer reviewed preprint, ${ }^{1}$ show that the risk of cerebral venous thrombosis "is many-fold higher after covid-19 than after receiving a vaccine," Maxime Taquet, NIHR academic clinical fellow in psychiatry at the University of Oxford and an author of the study, told journalists at a Science Media Centre briefing in London on 15 April. "That is the case, if you look at the Pfizer and Moderna vaccine [data] that we had direct access to, and that is also the case if you look at the Oxford-AstraZeneca vaccine, if you look at data from the European Medicines Agency."

Using data from a large US electronic health records, the researchers compared the incidence of cerebral venous thrombosis in patients two weeks after a covid-19 diagnosis with that in patients two weeks after covid-19 vaccination.

In the 513284 patients with a covid-19 diagnosis the incidence of cerebral venous thrombosis was 39.0 per million people ( $95 \%$ confidence interval 25.2 to 60.2 million), and in the 489871 patients who had received covid-19 vaccination the incidence was 4.1 per million (1.1 to 14.9 million) (adjusted relative risk 6.36, $\mathrm{P}<0.001)$. Vaccinated patients received an mRNA vaccine, either the Pfizer-BioNTech one or Moderna's.

None of the patients received the

AstraZeneca-University of Oxford vaccine, which has been linked to cases of rare cerebral blood clots, causing some governments and regulators to restrict its use, ${ }^{2}$ because that vaccine has not yet been authorised for use in the US.

The European Medicines Agency has estimated that the risk of cerebral venous thrombosis after the AstraZeneca vaccine is 5.0 (4.3 to 5.8) per million people.

Thrombocytopenia associated with an immune response has been implicated in cases of cerebral venous thrombosis after the AstraZeneca vaccine. Specifically, an antibody against platelet factor 4, which provokes blood clotting and consumes platelets, has been identified in patients who experienced the clots.

The mechanism involved in cerebral venous thrombosis after covid-19 disease may be different, but mortality after cerebral venous thrombosis in people who had had covid-19 was around $20 \%$ in the study, similar to the death rate from cerebral venous thrombosis associated with thrombocytopenia reported by the EMA in patients who received the AstraZeneca vaccine, said Taquet.

Around $30 \%$ of cerebral venous thrombosis events in covid-19 patients were in patients aged under 30 , he added.

Study patients were not matched for age or sex. This might affect the absolute risks and therefore the balance of benefits and harms between the disease and the vaccine in different groups of patients. Taquet said that the data did not indicate an obvious association with age and sex in the cerebral venous thrombosis events.

However, the UK Joint Committee on Vaccination and Immunisation recently recommended that people under 30 should be offered an alternative to the AstraZeneca vaccine. This decision was based on a comparison between intensive care admissions prevented by the vaccine and risk of blood clots relating to the vaccine. In all age and risk groups the potential benefits of vaccination far outstripped the potential harms, except people at low risk who were under $30 .^{3}$

This week US regulators paused the rollout of the Janssen (Johnson \& Johnson) covid-19 vaccine, which like the AstraZeneca vaccine uses a viral vector platform, after reports of a small number of blood clot cases in people who had received this vaccine. ${ }^{4}$

Taquet M, Husain M, Geddes JR, Luciano S, Harrison PJ. Cerebral venous thrombosis: a retrospective cohort study of 513284 confirmed COVID-19 cases and a comparison with 489871 people receiving a COVID-19 mRNA vaccine. https://osf.io/a9jdq/

2 Mahase E. Covid-19: AstraZeneca vaccine is not linked to increased risk of blood clots, finds European Medicine Agency. BMJ2021;372:n774. doi: 10.1136/bmj.n774 pmid: 33741638

3 Mahase E. AstraZeneca vaccine: Blood clots are "extremely rare" and benefits outweigh risks, regulators conclude. BM/2021;373:n931. doi: 10.1136/bmj.n931 pmid: 33832929

4 Mahase E. Covid-19: US suspends Johnson and Johnson vaccine rollout over blood clots. BMJ2021;373:n970. doi: 10.1136/bmj.n970 pmid: 33849896

This article is made freely available for use in accordance with BMJ's website terms and conditions for the duration of the covid-19 pandemic or until otherwise determined by BMJ. You may use, download and print the article for any lawful, non-commercial purpose (including text and data mining) provided that all copyright notices and trade marks are retained. 